\title{
Penerapan Algoritma K-Nearest Neighbor Untuk Klasifikasi Efektivitas Penjualan Vape (Rokok Elektrik) pada "Lombok Vape On"
}

\author{
Yahya $^{1 *}$, Winda Puspita Hidayanti ${ }^{2}$ \\ 1,2Program Studi Sistem Informasi, Universitas Hamzanwadi \\ *ayhay7078@gmail.com
}

\begin{abstract}
Abstrak
Perusahaan yang dibangun dengan tujuan untuk menghasilkan barang atau jasa yang ditujukan untuk memenuhi kebutuhan konsumen juga untuk memperoleh keuntungan bagi perusahaan tersebut. Perusahaan sudah tentu memiliki tujuan yang sama yaitu mencapai target yang sudah direncanakan dan mampu menghasilkan pemasukan yang selalu meningkat disetiap tahunnya. Dan salah satu kegiatan usaha yang harus dilakukan agar perusahaan tetap berjalan dan berkembang adalah penjualan. Keputusan yang diambil pemegang tanggung jawab perusahaan akan mempengaruhi perusahaan dimasa depan. Salah satu keputusan yang harus ditentukan yaitu produk yang akan diproduksi dan dijual untuk periode selanjutnya. Dilihat dari era globalisasi saat ini bahwa usaha yang dapat mengikuti zaman yaitu produk rokok elektrik (Vape). Produk tersebut benar-benar diminati oleh kalangan anak muda hususnya para pria. Salah satu instansi yang mengambil keputusan untuk menggeluti bisnis tersebut yaitu Lombok Vape On. "Lombok Vape On" memiliki konsumen yang cukup banyak sehingga pendapatan yang didapat tentu banyak, akan tetapi pendapatannya tidak menentu dan tidak dapat diprediksi dengan baik setiap bulannya. Tujuan dari penelitian ini untuk mengklasifikasikan hasil penjualan dari Lombok Vape on untuk mengetahui efektifitas penjualan perbulannya agar toko tersebut dapat mengetahui pasang surut pemasukan yang didapat. Apabila instansi tersebut mengetahui tingkat penjualannya maka instansi tersebut dengan mudah mengubah strategi penjualan agar stabil dan meningkat. Untuk itu peneliti menerapkan metode KNearest Neighbor untuk mengklasifikasin masalah tersebut,dan diharapkan metode ini mampu mengatasi masalah pada "Lombok Vape On".
\end{abstract}

Kata Kunci : K-NN, Vape, Lombok Vape On

\begin{abstract}
Companies that are built with the aim of producing goods or services that are intended to meet the needs of consumers as well as to obtain profits for the company. The company certainly has the same goal which is to achieve the planned target and be able to generate revenue that is always increasing every year. And one of the business activities that must be done so that the company continues to run and develop is sales. The decision taken by the holder of corporate responsibility will affect the company in the future. One of the decisions that must be determined is the product to be produced and sold for the next period. Judging from the current era of globalization, businesses that can keep up with the times are electric cigarette products (vape). These products are really in demand by young people especially men. One of the agencies that made the decision to run the business was Lombok Vape On. Lombok Vape On has quite a lot of consumers so that the income earned is certainly a lot, but the income is uncertain and cannot be well predicted every month. The purpose of this study is to classify the sales results from Lombok Vape on to determine the effectiveness of monthly sales so that the store can know the ups and downs of income obtained. If the agency knows the level of sales, the agency can easily change the sales strategy to be stable and increase. For this reason researchers applied the K-Nearest Neighbor method to classify the problem, and it is hoped that this method is able to overcome the problem in Lombok Vape On.
\end{abstract}

Keywords: K-NN, Vape, Lombok Vape On 


\section{Pendahuluan}

Penjualan merupakan salah satu unsur penting dalam suatu bisnis di bidang pemasaran, setiap bisnis memiliki tujuan yang umum disetiap langkah dan prosesnya, tujuan yang dimaksud mampu mencapai target yang sudah direncanakan dan mampu menghasilkan pemasukan yang selalu meningkat disetiap tahunnya, selain itu bisnis yang baik memiliki tujuan jangka panjang supaya masa yang akan datang dapat mengalami perubahan ke arah yang lebih baik. Kegiatan perusahaan yang bisa menghasilkan keuntungan adalah penjualan, dan penjualan merupakan salah satu faktor terpenting dalam bisnis. Dengan adanya perkembangan yang semakin pesat di era globalisasi ini, pebisnis berlomba-lomba untuk mendapatkan banyak keuntungan dengan berbagai macam kegiatan penjualan dimana semakin banyak barang yang terjual maka semakin banyak pula keuntungan yang dicapai. Salah satu bisnis yang fenomena dikalangan masyarakat saat ini yaitu bisnis Vape (Rokok Elektrik) dimana belakangan ini kita tahu bahwa rokok elektrik sudah mulai diminati oleh masyarakat banyak terutama pada perkembangan gaya hidup dikalangan pria, namun selain pria, saat ini wanita remaja juga menjadi salah satu peminat dari rokok elektrik tersebut. Salah satu toko di Nusa Tenggara Barat yang memilih untuk mendirikan bisnis rokok elektrik yaitu "Lombok Vape on", toko tersebut menghasilkan penjualan yang cukup besar setiap tahun, tetapi hasil penjualan yang dihasilkan tidak stabil dan tidak mampu diprediksi kenaikan dan penurunan penjualannya.

Dari penelitian yang dilakukan, berusaha untuk mengklasifikasikan hasil penjualan dari "Lombok Vape On" untuk mengetahui efektifitas penjualan. Data yang digunakan adalah data hasil penjualan tahun 2019 dan mengklasifikasikan hasil penjualan pada "Lombok Vape On" berdasarkan jumlah item atau jenis barang yang mampu terjual.

Dengan melakukan klasifikasi pada toko tersebut dapat mengetahui pasang surut pemasukan yang didapat dari toko "Lombok Vape On". Untuk mengetahui efektifitas dari toko tersebut, dilakuakn dengan menggunakan salah satu metode dalam data mining yang merupakan proses yang menggunakan teknik statistik, matematika, kecerdasan buatan, machine leraning untuk mengekstraksi dan mengidentifikasi informasi yang bermanfaat dan pengetahuan yang terkait dari berbagai database yang besar, sedangkan metode yang digunakan yaitu metode K-Nearest Neighbor.

Kelebihan menggunakan metode K-Nearest Neighbor diperkirakan dapat memberikan hasil prosentase yang cukup bagus sehingga prosentase yang dihasilkan mampu membuat toko "Lombok Vape On" mengetahui pasang surut dari hasil penjualan. Apabila toko mengetahui peningkatan atau penurunan dari hasil penjualannya maka toko dapat segera mengambil tindakan untuk mengubah dan meningkatkan strategi yang jauh lebih baik lagi. 
Berdasarkan uraian di atas, maka penelitian yang dilakukan adalah Penerapan Algoritma KNearest Neighbor Untuk Klasifikasi Efektivitas Penjualan Vape (Rokok Elektrik) Pada "Lombok Vape On".

\section{Tinjauan Pustaka}

\subsection{Penelitian terkait}

Dalam penulisan skripsi ini, penulis terinspirasi menggunakan referensi dari penelitian-penelitian sebelumnya yang berkaitan dengan pembahasan skripsi yang dibuat. Penelitian ini terkait penggunaan data mining dengan menggunakan algoritma K-Nearest Neighbor. Berikut ini penelitian terdahulu yang berkaitan dengan proposal skripsi antara lain:

- Penelitian yang dilakukan (Resti Hutami, 2016), algoritma ini digunakan untuk melakukan prediksi data penjualan furniture pada CV. Octo Agung Jepara. Hasil penelitian menunjukan metode yang diusulkan berhasil diimplementasikan untuk menyelesaikan kasus prediksi penjualan dengan tingkat error sebesar 6 persen dan akurasi 94 persen[1].

- Penelitian yang dilakukan oleh Nobertus Krisandi. Dkk dengan judul "Algoritma KNearest Neighbor dalam Klasifikasi Data Hasil Produksi Kelapa Sawit pada PT. Minamas Kecamatan Parindu". Data yang digunakan adalah data hasil produksi kelapa sawit (Tonase) dari 50 kelompok tani pada periode Juli-Desember 2011 pada PT. Minasa Kabupaten Sanggau. Nilai k yang digunakan adalah $\mathrm{k}=1, \mathrm{k}=3, \mathrm{k}=5$ dan $\mathrm{k}=7$. Hasil penelitian menunjukkan bahwa, hasil produksi yang dominan adalah dengan nilai $\mathrm{k}=7$ sebesar yang memiliki nilai accuracy sebesar 34\%. Hal tersebut juga mengindikasikan bahwa K-Nearest Neighbor (KNN) dipengaruhi oleh jumlah klastering data[2].

- Penelitian yang dilakukan oleh Ricky Imanuel Ndaumanu, Kusrini, M. Rudyanto Arief yang berjudul Analisis Prediksi Tingkat Pengunduran Diri Mahasiswa Dengan Metode K-Nearest Neighbor. Pada penelitian ini, dikemukakan bahwa dari jumlah pendaftaran mahasiswa baru ini, banyak juga mahasiswa yang mengundurkan diri setiap tahunnya yang disebabkan berbagai masalah. Oleh karena adanya mahasiswa yang mengundurkan diri, penulis melakukan analisis pengunduran diri mahasiswa menggunakan algoritma K-Nearest Neighbor. Penelitian ini bertujuan untuk memprediksi seberapa tingkat akurasi pengunduran diri mahasiswa STIKOM UYELINDO Kupang.[3].

\subsection{Landasan Teori}

\section{Pengertian Data Mining}

Data mining merupakan disiplin ilmu yang mempelajari metode untuk mengekstrak pengetahuan atau menemukan pola dari suatu data. Data mining adalah suatu metode pengolahan data untuk menemukan pola yang tersembunyi dari data tersebut. Hasil dari 
pengolahan data dengan metode data mining ini dapat digunakan untuk mengambil keputusan di masa depan. Salah satu teknik yang dibuat dalam data mining adalah bagaimana menelusuri data yang ada untuk membangun sebuah model, kemudian menggunakan model tersebut agar dapat mengenali pola data yang lain yang tidak berada dalam basis data yang tersimpan. Kebutuhan untuk prediksi juga dapat memanfaatkan teknik ini. Dalam data mining, pengelompokan data juga bisa dilakukan. Tujuannya adalah agar kita dapat mengetahui pola universal data-data yang ada[1].

\section{Pengertian Penerapan}

Menurut Kamus Besar Bahasa Indonesia (KBBI), pengertian penerapan adalah perbuatan menerapkan, sedangkan menurut beberapa ahli, penerapan adalah suatu perbuatan mempraktekkan suatu teori, metode, dan hal lain untuk mencapai tujuan tertentu dan untuk suatu kepentingan yang diinginkan oleh suatu kelompok atau golongan yang telah terencana dan tersusun sebelumnya.

\section{Tahapan Data Mining}

Menurut Fayyad, 1996 dalam jurnal Yuli Sudriani yang berjudul "Tren Analisa Data Berskala Besar Terkait Penelitian Ekologi" menyatakan tahapan yang dilakukan pada proses data mining diawali dari seleksi data dari data sumber ke data target, tahap preprocessing untuk memperbaiki kualitas data, transformasi, data mining serta tahap interpretasi dan evaluasi yang menghasilkan output berupa pengetahuan baru yang diharapkan memberikan kontribusi yang lebih baik secara detail dijelaskan sebagai berikut :

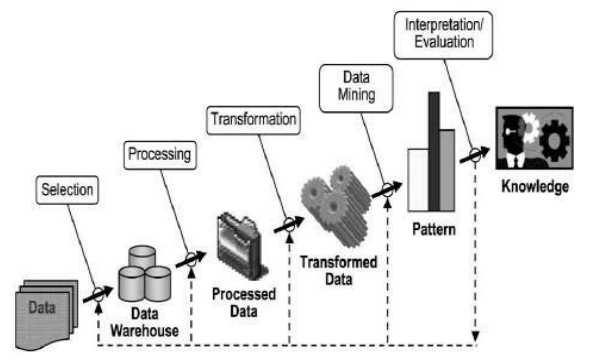

Gambar 1. Tahapan data mining

a. Data Selection

Pemilihan (seleksi) data dari sekumpulan data operasional. Data hasil seleksi akan digunakan untuk proses data mining, dan disimpan dalam suatu berkas dan terpisah dari basis data operasional.

b. Cleaning Data

Proses cleaning dilakukan dengan menghilangkan noise, membuang duplikasi data, memeriksa data yang tidak konsisten, dan memperbaiki kesalahan pada data, seperti kesalahan cetak (tipografi).

c. Transformasi Data

Tahap ini merupakan proses transformasi pada data yang telah dipilih, sehingga data tersebut sesuai untuk proses data mining.

d. Data mining

Data mining merupakan proses mencari pola atau informasi yang sangat menarik dalam data terpilih dengan menggunakan teknik atau metode tertentu.

e. Interpretation/Evalution

Tahap ini mencakup pemeriksaan apakah pola atau informasi yang ditemukan 
bertentangan dengan fakta atau hipotesis yang ada sebelumnya.

\section{Klasifikasi}

Klasifikasi adalah satu bentuk analisis data yang menghasilkan model untuk mendeskripsikan kelas data yang penting. Klasifikasi memprediksi kategori ke dalam label class. Klasifikasi merupakan proses untuk menemukan model atau fungsi yang menjelaskan atau membedakan konsep atau class data, dengan tujuan untuk dapat memperkirakan kelas dari suatu objek yang labelnya tidak diketahui[2].

Algoritma klasifikasi yang banyak digunakan secara luas, yaitu Decision/Classification Trees, Bayesian Classifiers/Naïve Bayes Classifiers, Neural Networks, Analisa Statistik, Algoritma Genetika, Rough Sets, K-Nearest Neighbor, Metode Rule Based, Memory Based Reasoning, dan Support Vector Machines (SVM). Proses klasifikasi didasarkan pada empat komponen (Gorunescu, 2011) [3]:

a. Kelas

Variabel dependen yang berupa kategorikal yang merepresentasikan label yang terdapat pada objek. Contohnya: resiko penyakit jantung, resiko kredit, customer loyalty, jenis gempa. J Piksel 1(1) : 65 -76 (2013).

b. Predictor Variabel independen

Predictor Variabel independenyang direpresentasikan oleh karakteristik (atribut) data. Contohnya: merokok, minum alkohol, tekanan darah, tabungan, aset, gaji. c. Training Datasets

Training dataset satu set data yang berisi nilai dari kedua komponen di atas yang digunakan untuk menentukan kelas yang cocok berdasarkan predictor.

d. Testing dataset

Testing dataset berisi data baru yang akan diklasifikasikan oleh model yang telah dibuat dan akurasi klasifikasi dievaluasi.

\section{Algoritma K-NN (K-Nearest Neighbor)}

K-Nearest Neighbor (K-NN) adalah suatu metode yang menggunakan algoritma supervised dimana hasil dari sampel uji yang baru diklasifikasikan berdasarkan mayoritas dari kategori pada K-NN. Tujuan dari algoritma ini adalah mengklasifikasi objek baru berdasakan atribut dan sampel latih. Pengklasifikasian tidak mengguna kan model apapun untuk dicocokkan dan hanya berdasarkan pada memori. Diberikan titik uji, akan ditemukan sejumlah $\mathrm{K}$ objek (titik training) yang paling dekat dengan titik uji. Klasifikasi menggunakan voting terbanyak di antara klasifikasi dari $\mathrm{K}$ objek. Algoritma K-NN menggunakan klasifikasi ketetanggaan sebagai nilai prediksi dari sampel uji yang baru. Dekat atau jauhnya tetangga biasanya dihitung berdasarkan jarak Eucledian[4].

Langkah-langkah untuk menghitung algoritma KNearest Neighbor:

- Menentukan parameter K (Jumlah tetangga paling dekat). 
- Menghitung kuadrat jarak Euclid (queri instance) masing-masing objek terhadap data sampel yang diberikan.

- Kemudian mengurutkan objek-objek tersebut ke dalam kelompok yang mempunyai jarak Euclid terkecil.

- Mengumpulkan kategori Y (Klasifikasi Nearest Neighbor)

Ada banyak cara untuk mengukur jarak kedekatan antara data baru dengan data lama (data training), diantaranya euclidean distance dan manhattan distance (city block distance), yang paling sering digunakan adalah euclidean distance (Bramer,2007), yaitu[5]:

$\sqrt{(a 1-b 1)^{2}+(a 2-b 2)^{2}+.+(a n-b n)^{2}}$

Dimana $a=a 1, a 2, \ldots$, an, dan $b=b 1, b 2, \ldots, b n$ mewakili $n$ nilai atribut dari dua record. Untuk atribut dengan nilai kategori, pengukuran dengan euclidean distance tidak cocok. Sebagai penggantinya, digunakan fungsi sebagai berikut (Larose, 2006):different(ai,bi) $=\{0 j \mathrm{jka} \quad$ ai $=$ bi1 selainnya. Dimana ai dan bi adalah nilai kategori. Jika nilai atribut antara dua record yang dibandingkan sama maka nilai jaraknya 0 , artinya mirip, sebaliknya, jika berbeda maka nilai kedekatannya 1 , artinya tidak mirip sama sekali. Misalkan atribut warna dengan nilai merah dan merah, maka nilai kedekatannya 0 , jika merah dan biru maka nilai kedekatannya 1.

Untuk menghitung kemiripan kasus, digunakan rumus (Kusrini, 2009):

$$
\begin{aligned}
& \operatorname{Similarity}(p, q) \\
& =\frac{n \sum_{t=1}^{n} f(p i, q i) \mathrm{X} \mathrm{wi}}{\mathrm{wi}}
\end{aligned}
$$

Keterangan :

$\mathrm{P}=$ Kasus baru

$q=$ Kasus yang ada dalam penyimpanan

$\mathrm{n}=$ Jumlah atribut dalam tiap kasus

$i=$ Atribut individu antara 1 sampai dengan $n$

$f=$ Fungsi similarity atribut $i$ antara kasus $p$ dan kasus q

$w=$ Bobot yang diberikan pada atribut ke-i.

\section{Definisi Dataset}

Untuk istilah mainframe IBM untuk suatu file, lihat Kumpulan data (mainframe IBM). Untuk perangkat antarmuka telekomunikasi, lihat Modem. Kumpulan data (atau dataset) adalah kumpulan data. Dalam kasus data tabular, satu set data sesuai dengan satu atau lebih tabel database, di mana setiap kolom tabel mewakili variabel tertentu, dan setiap baris sesuai dengan catatan tertentu dari set data yang dimaksud. Kumpulan data mencantumkan nilai untuk setiap variabel, seperti tinggi dan berat objek, untuk setiap anggota kumpulan data. Setiap nilai dikenal sebagai datum. Kumpulan data juga dapat terdiri dari kumpulan dokumen atau file.

\section{RapidMiner}

RapidMiner merupakan perangkat lunak yang dibuat oleh Dr. Markus Hofmann dari Institute of Technologi Blanchardstown dan Ralf Klinkenberg dari rapid-i.com dengan tampilan GUI (Graphical User Interface) sehingga memudahkan pengguna dalam menggunakan perangkat lunak ini. Perangkat lunak ini bersifat open source dan dibuat dengan menggunakan program Java di 
bawah lisensi GNU PublicLicence dan RapidMiner dapat dijalankan di sistem operasi manapun. Dengan menggunakan RapidMiner, tidak dibutuhkan kemampuan koding khusus, karena semua fasilits sudah disediakan. RapidMiner dikhususkan untuk penggunaan data mining. Model yang disediakan juga cukup banyak dan lengkap, seperti Model Bayesian, Modelling, Tree Induction, Neural Network dan lain-lain. Banyak metode yang disediakan oleh RapidMiner mulai dari klasifikasi, klustering, asosiassi dan lain-lain.

\section{Metode Penelitian}

\subsection{Teknik Pengumpulan Data}

Untuk memperoleh data yang digunakan dalam penelitian ini, ada beberapa metode yang digunakan antara lain :

- Observasi

Teknik observasi yang dilakukan adalah mengumpulkan data dengan melakukan obsevasi atau pengamatan langsung ke Lombok Vape On untuk melakukan penelitian dan mencari informasi-informasi yang dibutuhkan dalam menyelesaikan penelitian ini.

- Interview (Wawancara)

Melakukan komunikasi langsung dengan teknik tanya jawab atau wawancara dengan pemilik toko Lombok Vape On.

- Studi pustaka

Suatu metode pengumpulan data dengan cara membaca dan mempelajari buku-buku yang berhubungan dengan penelitian ini, serta referensi yang terkait dengan topik yang akan dibahas dalam penyusunan skripsi ini, serta mengunjungi (Browsing) situs-situs internet yang berhubungan dengan skripsi.

\subsection{Teknik Pemrosesan Data}

1. Eksperimen Algoritma K-Nearest Neighbor

Data berikut adalah datasets penjualan pada "Lombok Vape On". Dimana terdapat 9 record untuk data training yaitu no 1-9 dan 1 data testing yaitu no 10 .

Tabel 1. Data Seleksi

\begin{tabular}{|r|l|r|r|r|l|}
\hline No & Jenis & Keuntungan & Pendapatan & Jumlah & Kategori \\
\hline 1 & Wrap baterai & 251.2 & 538.2 & 287 & Mencapai target \\
\hline 2 & Aegis boost & 5.060 .000 & 42.500 .000 & 104 & Mencapai target \\
\hline 3 & Coil aegis Boost 04 & 1.505 .000 & 5.465 .000 & 132 & Mencapai target \\
\hline 4 & Coil gear 300mah & 3.860 .000 & 9.340 .000 & 137 & Mencapai target \\
\hline 5 & Gold cotton kecil & 1.720 .000 & 3.330 .000 & 209 & Mencapai target \\
\hline 6 & One fire & 6.940 .000 & 9.980 .000 & 304 & Mencapai target \\
\hline 7 & Smok coil 40 rpm & 129 & 5.065 .000 & 123 & Mencapai target \\
\hline 8 & Smok rpm coil 03 & 1.756 .000 & 5.910 .000 & 134 & Mencapai target \\
\hline 9 & Voopoo vinci coil & 1.841 .000 & 7.756 .000 & 169 & Mencapai target \\
\hline 10 & Kawat koil & 1.260 .000 & 2.820 .000 & 312 & $?$ \\
\hline
\end{tabular}

Langkah-langkah dari algoritma K-Nearest

Neighbor:

- Penentuan parameter $k=5$ (jumlah tetangga paling dekat). Disini dalam penentuan parameter $\mathrm{k}=5$

- Menghitung Eucliden distance)

Tabel 2. Hasil Euclidean distance

\begin{tabular}{|l|l|r|r|r|l|l|}
\hline No & \multicolumn{1}{|c|}{ Jenis } & \multicolumn{1}{c|}{ Profit } & \multicolumn{1}{c|}{ Pend. } & \multicolumn{1}{c|}{ Qty } & \multicolumn{1}{c|}{ Rem } & ED \\
\hline 1 & $\begin{array}{l}\text { Wrap } \\
\text { baterai }\end{array}$ & 251.2 & 538.2 & 287 & OK & 2494852.4 \\
\hline 2 & Aegis boost & 5.060 .000 & 42.500 .000 & 104 & $\mathrm{OK}$ & 39861540 \\
\hline 3 & $\begin{array}{l}\text { Coil aegis } \\
\text { Boost 04 }\end{array}$ & 1.505 .000 & 5.465 .000 & 132 & $\mathrm{OK}$ & 2656322.7 \\
\hline 4 & $\begin{array}{l}\text { Coil gear } \\
\text { 300mah }\end{array}$ & 3.860 .000 & 9.340 .000 & 137 & $\mathrm{OK}$ & 7019287.7 \\
\hline 5 & $\begin{array}{l}\text { Gold cotton } \\
\text { kecil }\end{array}$ & 1.720 .000 & 3.330 .000 & 209 & $\mathrm{OK}$ & 656804.2 \\
\hline 6 & One fire & 6.940 .000 & 9.980 .000 & 304 & $\mathrm{OK}$ & 9139365.4 \\
\hline 7 & $\begin{array}{l}\text { Smok coil } \\
40 \text { rpm }\end{array}$ & 129 & 5.065 .000 & 123 & $\mathrm{OK}$ & 2513799.1 \\
\hline 8 & $\begin{array}{l}\text { mmok rpm } \\
\text { coil 0 3 }\end{array}$ & 1.756 .000 & 5.910 .000 & 134 & $\mathrm{OK}$ & 3129555.2 \\
\hline 9 & $\begin{array}{l}\text { Voopoo } \\
\text { vinci coil }\end{array}$ & 1.841 .000 & 7.756 .000 & 169 & $\mathrm{OK}$ & 4970076.2 \\
\hline
\end{tabular}


- Mengurutkan objek-objek tersebut kedalam kelompok yang mempunyai jarak Euclidian terkecil. Untuk mengurutkannya kita hanya perlu membuat urutan dari data yang mempunyai jarak terkecil ke data terbesar.

Tabel 3 Urutan Jarak Euclidian terkecil

\begin{tabular}{|l|l|l|c|}
\hline No & \multicolumn{1}{|c|}{ Jenis } & \multicolumn{1}{|c|}{ Distance } & Rank \\
\hline 1 & Aegis boost & 39861540.36 & 1 \\
\hline 2 & One fire & 9139365.405 & 2 \\
\hline 3 & Coil gear 300mah & 7019287.715 & 3 \\
\hline 4 & Voopoo vinci coil & 4970076.158 & 4 \\
\hline 5 & Smok rpm coil 0 3 & 3129555.245 & 5 \\
\hline 6 & Coil negis Boost 04 & 2656322.652 & 6 \\
\hline 7 & Smok coil 40 xpm & 2513799.124 & 7 \\
\hline 8 & Wrap baterai & 2494852.437 & 8 \\
\hline 9 & Gold cotton kecil & 686804.2011 & 9 \\
\hline
\end{tabular}

- Mengumpulkan kategori Y (Klasifikasi Nearest Neighbor). Pada tahap ini hanya mengambil data sesuai dengan jumlah $\mathrm{k}$ yang kita tentukan adalah $k=5$. Jadi, kita memilih 5 data yang memiliki Euclid terkecil, dan hasilnya sebagai berikut :

Tabel 4. Urutan kategori Y

\begin{tabular}{|c|l|c|c|}
\hline No & \multicolumn{1}{|c|}{ Jenis } & Distance & Rangking \\
\hline 1 & Aegis boost & 39861540.36 & 1 \\
\hline 2 & One fire & 9139365.405 & 2 \\
\hline 3 & Coil gear 300mah & 7019287.715 & 3 \\
\hline 4 & Voopoo vinci coil & 4970076.158 & 4 \\
\hline 5 & Smok rpm coil 0 3 & 3129555.245 & 5 \\
\hline
\end{tabular}

- Dengan menggunakan kategori mayoritas, maka didapat hasil klasifikasi dan pengolahan seperti tabel di bawah:

Tabel 5. Urutan kategori mayoritas

\begin{tabular}{|c|c|c|c|c|}
\hline No & Jenis & Disance & Rending & Kanegori \\
\hline 1 & Aregis boost & 39581540.36 & 1 & Mencapai target \\
\hline 2 & Oat fre & 9139365.405 & 2 & Menciapai turget \\
\hline 3 & Col gear 300ash & 7019287.715 & 3 & Mencapai target \\
\hline 4 & Voopoo vinei col & 4970076.158 & 4 & Mencapoi traget \\
\hline 5 & Smok ren col 03 & 3129555245 & 5 & Mencapai target \\
\hline
\end{tabular}

Data yang memiliki Euclid terkecil adalah data ke 2, 6, 4, 9, 8 dari data yang sudah diuji tersebut terdapat semua data mencapai target. Sehingga mayoritas data mampu mencapai target. Jadi hasil klasifikasi dan pengolahan untuk kawat koil dalah penyandang mencapai target.

\section{Pengujian Algoritma}

Diperlukan beberapa tahapan untuk mengolah data yaitu:

a. Untuk menganalisa, dibutuhkan data training yang akan diolah dan dimasukkan kedalam Rapidminer dan menggunakan berbagai macam format seperti csv, xls, mdb, dan lain-lain. Adapun format data yang digunkan oleh penulis yaitu xls.

b. Buka aplikasi rapidminer, kemudian akan tampil halaman awal, selanjutnya kelik File dan pilih New Proses.

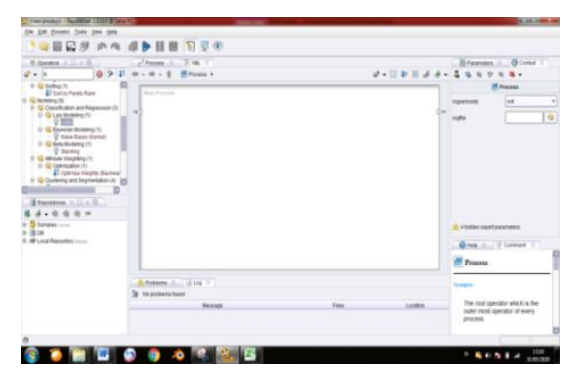

Gambar 2. Tampilan kerja Rapidminer

c. Memasukkan data yang akan diolah dan sesuikan format data yang dimiliki oleh peneliti, dan disini peneliti menggunakan format xls kemudian kelik pada pencarian atau [filter] di Rapidminer seperti pada gambar di bawah ini, Kemudian pilih Import Wizard. 


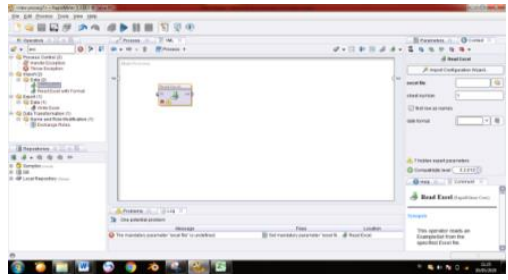

Gambar 3. Pemilihan format data

d. Tampilan data untuk import wizard diperlukan 5 langkah dalam tahapan ini, langkah ke-1 tentukan nama file yang berisi data training yang akan dimasukkan dan selanjutnya klik next pada gambar di bawah ini.

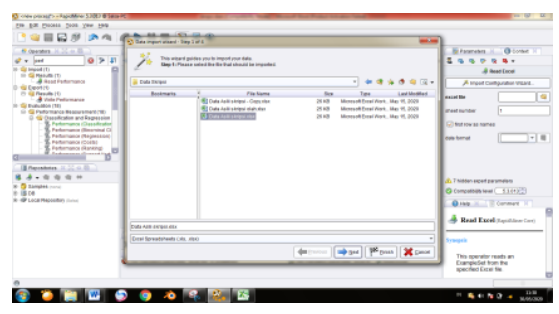

Gambar 4. Pemilihan Data

e. Tampilan data untuk menentukan tempat data tersimpan, selanjutnya klik next pada gambar di bawah ini:

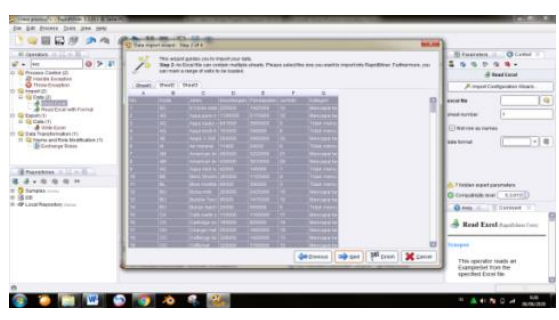

Gambar 5 Tampilan sheet data

f. Tampilan untuk melihat data yang kosong, atau data yang tidak dapat diolah. Selanjutnya klik next pada gambar di bawah ini:

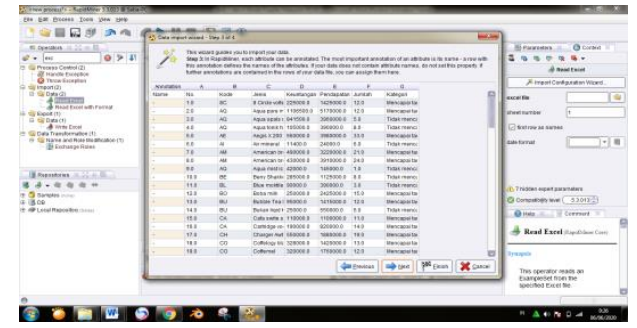

Gambar 6. Tampilan pengecekan data

g. Tahapan ini dilakukan untuk menentukan label pada data, dan apabila ada atribut yang tidak diperlukan, hilangkan centang paling atas sesuaikan urutan dari atribut yang tidak diperlukan tersebut. Kemudian pilih finish untuk masuk ke tahap selanjutnya, seperti gambar di bawah ini:

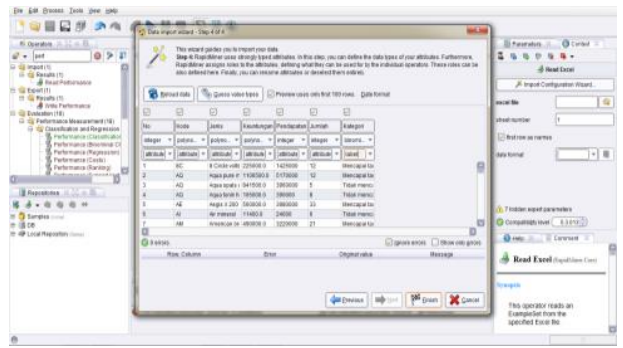

Gambar 7. Pemilihan tabel atribut dan label

h. Tahapan ini dilakukan untuk menambahkan model algoritma yang dibutuhkan, pilih Tab Operator- Modelling-Classification and Regression-Lazy Modelling- k-NN. Apabila sudah terpilih algortima terebut selanjutnya Geser k-NN ke arah Main Process dan hubungkan seperti gambar di bawah ini :

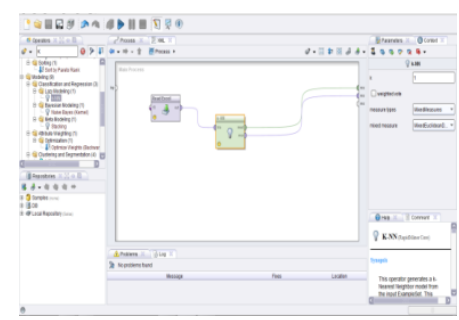

Gambar 8. Relasi data training dengan model

i. Tampilan untuk melihat hasil dari pengolahan menggunakan algoritma $K$ Nearest Neighbor, pilih menu Process-Run maka akan tampil hasil seperti berikut ini : 


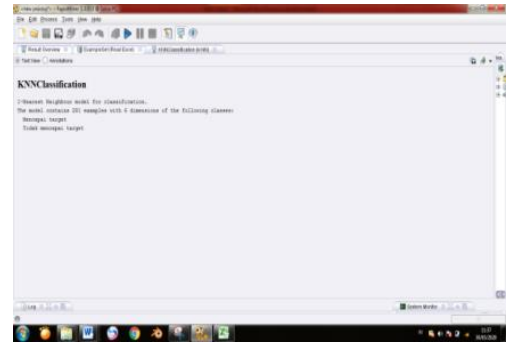

Gambar 9. Relasi data training dengan model

\section{Hasil dan Pembahasan}

1. Cros validation

Pengujian ini menggunakan 281 data, pengujian ini juga dilakukan untuk mengetahui pengaruh nilai $\mathrm{k}$ terhadap tingkat akurasi data, semakin tinggi jumlah $\mathrm{k}$ yang digunakan maka akan semakin bagus hasil dari pengujian. Nilai $k$ yang terbaik pada algoritma ini tergantung pada jenis data yang digunakan. Nikai $k$ yang bagus dapat dipilih dengan optimasi parameter, contohnya dengan menggunakan cross validation. Dalam kasus khusus, klasifikasi K-Nearest Neighbor dapat diprediksi berdasarkan training data yang paling dekat (dengan kata lain $k=1$ ). Nilali $k$ (ketetanggaan paling dekat) yang digunakan dalam penelitian ini adalah 1, 2, 3, 4, 5, 6, 7, 8, 9, 10 dengan cross validation 10 .

\begin{tabular}{|c|c|c|c|}
\hline \multicolumn{4}{|c|}{ 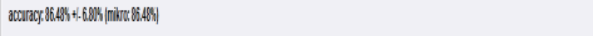 } \\
\hline & teellanarabarat & 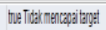 & dasprobian \\
\hline 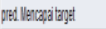 & 181 & $\pi$ & $8786 \%$ \\
\hline 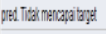 & 21 & 12 & 86314 \\
\hline dassinal & 86244 & $877 \%$ & \\
\hline
\end{tabular}

Algoritma K-Nearest Neighbor akan melakukan training terhadap data yang telah dipisahkan oleh Cross Validation menjadi dua tempat yaitu satu tempat untuk data training dan satu tempat untuk data testing. Training terdiri dari metode $K$ Nearest Neighbor yang digunakan dan testing terdiri dari apply model dan performance.

\section{Confusion Matrix}

Jumlah true positif (TP) adalah 121 record diklasifikasikan sebagai class yang mencapai target dan false negatif (FN) sebanyak 21 record diklasifikasikan sebagai class yang mencapai target namun pada kenyataannya adalah berada pada class yang tidak mencapai target. Berikutnya 122 record false positif (TN) diklasifikasikan sebagai class yang tidak mencapai target, dan 17 record false positif (FP) diklasifikasikan sebagai class yang tidak mencapai target namun ternyata diklasifikasikan sebagai class yang mencapai target. Berdasarkan Tabel 8 menunjukkan bahwa tingkat akurasi menggunakan algoritma $K$ Nearest Neighbor dengan K-Fold Validation 6 adalah sebesar $86.48 \%$, dan dapat dihitung untuk mencari nilai accuracy, sensitivity, specificity, Ppv dan Npv pada persamaan di bawah ini.

\section{Kurva ROC}

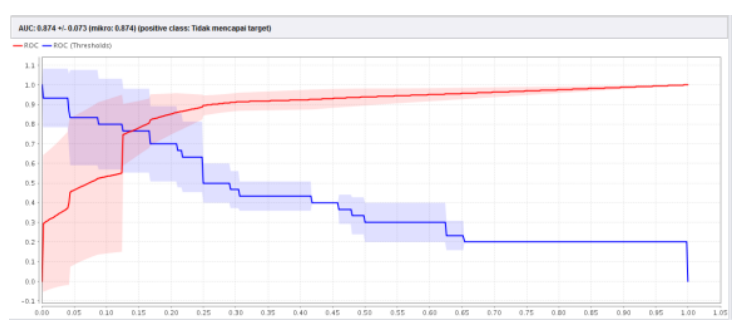

Gambar di atas adalah grafik ROC dengan nilai AUC (Area Under Curve) dengan hasil accuracy dengan K-Fold Validation 6 sebesar 86.48\% dengan nilai akurasi Excellent Classification.

\section{Kesimpulan}

Berdasarkan hasil penelitian yang dilakukan, dapat disimpulkan bahwa data penjualan yang 
telah diolah dengan menerapkan teknik data mining menggunakan algoritma K-Neraest Neighbor. Dari data penjualan dapat diketahui bahwa rata-rata jumlah satu jenis barang penjualan 10 pcs dapat disebut sebagai kategori mampu mencapai target dan apabila kurang dari 10 pcs yang terjual maka akan disebut dengan kategori tidak mampu mencapai target. Dari kategori tersebut dapat diketahui hasil pengolahan jumlah barang yang paling banyak terjual oleh toko bisnis Lombok Vape On. Pengujian ini dilakukan dengan cara menghitung sesuai dengan langkah-langkah algoritma K-NN (K-Nearest Neighbor) untuk menghasilkan model sehingga masuk dalam kategori excellent classification, pengolahan dilakukan dengan menggunakan 9 Validation, dari pengolahan tersebut terdapat K-Fold Validation 6 menjadi percobaan yang memiliki akurasi tertinggi. Dari percobaan yang telah dilakukan dapat diketahui hasil nilai K-Fold Validation 6 dengan hasil akurasi diperoleh sebesar $86.48 \%$ dan AUC sebesar 0.874 . Oleh karena itu metode algoritma K-Nearest Neighbor merupakan salah satu algoritma klasifikasi yang baik digunakan dan mampu mengklasifikasikan jumlah barang yang dapat terjual paling banyak. Adapaun jenis barang yang dikategorikan terjual paling banyak oleh toko bisnis tersebut yaitu jenis barang Aegis boost, One fire, Coil gear 300mah, Voopoo vinci coil, Smok rpm coil 0 3. Sehingga dalam menganalisa data metode ini cukup akurat untuk menganalisis data penjualan yang dikategorikan jenis barang paling dominan.

\section{Daftar Pustaka}

[1] R. A. Pangestu, S. Rudiarto, and D. Fitrianah, "Aplikasi Web Berbasis Algoritma K-Nearest Neighbour Untuk Menentukan Klasifikasi Barang Studi Kasus : Perum Peruri," vol. 2, no. 1, 2018.

[2] B. Sawit, S. Bss, and M. Metode, "Data Mining Untuk Memprediksi Hasil Produksi Buah Sawit Pada Pt Bumi Sawit Sukses (Bss) Menggunakan Metode K-Nearest Neighbor", pp. 198-207, 2019.

[3] H. B. Suhartini1, "Klasifikasi Algoritma KNearest Neighbor Berbasis Particle Swarm Optimization Untuk Kelayakan Bantuan Rehabilitasi Rumah Tidak Layak Huni Pada Desa Lenek Duren Kecamatan Aikmel Kabupaten Lombok Timur Suhartini1,Hariman," vol. 2, no. 2, pp. 7985, 2019.

[4] Yahya, "Prediksi Jumlah Penggunaan BBM Perbulan Menggunakan Algoritma Decition Tree(C4.5)," vol. 1, no. 1, pp. 56-63, 2018.

[5] M. Rivki and A. M. Bachtiar, "Implementasi Algoritma K-Nearest Neighbor Dalam Pengklasifikasian Follower Twitter Yang Menggunakan Bahasa Indonesia," J. Sist. Inf., vol. 13, no. 1, p. 31, 2017.

[6] Y. A. Setianto, K. Kusrini, and H. Henderi, "Penerapan Algoritma K-Nearest Neighbour Dalam Menentukan Pembinaan Koperasi Kabupaten Kotawaringin Timur," Creat. Inf. Technol. J., vol. 5, no. 3, p. 232, 2019.

[7] U. B. Rahayu, U. Islam, N. Sunan, and G. Djati, "Penerapan Algoritma K-Nearest Neighbor Dan Algoritma Simple Multi Attribute Rating Technique Untuk Menentukan Strategi Penjualan Pada Pt . Inti ( Persero )," 2016.

[8] B. SAWIT, S. BSS, AND M. METODE, "Data Mining Untuk Memprediksi Hasil Produksi Buah Sawit Pada Pt Bumi Sawit Sukses (Bss) Menggunakan Metode KNearest Neighbor," PP. 198-207, 2019. 